\title{
O Modelo Poligonal: uma revisão do Pentatlo de Peter Low
}

\author{
Eduardo Friedman*
}

\section{O pentatlo}

No texto “The Pentathlon Approach to Translating Songs" (2005), Peter Low, pensando no skopos de traduzir uma canção para ser cantada, indicou cinco parâmetros nos quais, como um pentatlo, o tradutor precisa ter uma performance satisfatória. São eles: singability (cuidados fonético-fonológicos que variam de língua para língua), sense (correspondência de sentido entre o original e a tradução), naturalness (registro e ordem de palavras), rhythm (variações na melodia) e rhyme (estrutura de rimas). Tomando como base as ideias de Low, propõe-se abaixo um modelo e uma forma de avaliação mais voltados à tradução de canções populares, que possuem algumas diferenças importantes em relação à música clássica, algo que o autor não aborda. Inclusive, os termos "música clássica" e "música popular" são vagos e de difícil delimitação; são muitas possíveis variações. O recorte aqui usado de música clássica é a música de concerto europeia, definida como

\footnotetext{
[o]bras compostas durante o chamado Período da Prática Comum, período que compreende o início e a dissolução do sistema tonal como prática composicional aceita e praticada pela maioria dos compositores e intérpretes, que geralmente é identificado como o repertório produzido entre os anos de 1650 e 1900. (RIBEIRO, 2017, p. 178)
}

Dessa forma, elimina-se do escopo de análise, por exemplo, a música renascentista, cuja escrita musical não empregava ritmos de notas, apenas alturas, e as várias vertentes da música clássica do século XX, que

* Pontifícia Universidade Católica do Rio de Janeiro (PUC-Rio). 
estabelecem para si outras regras. Este trabalho atém-se apenas à música clássica (i) centrada no registro textual (a partitura), (ii) mais rígida em termos de instrumentação e (iii) mais rígida em termos do que é considerado uma interpretação.

Já a música popular é a "música popular urbana ocidental do século XX" (ABREU, 2001, p. 106). É uma música (i) centrada no registro sonoro/audiovisual (a performance), (ii) mais livre em termos de instrumentação e (iii) mais livre em termos do que é considerado uma interpretação.

Algumas das ideias apresentadas por Low merecem uma atenção maior, e questionamentos advindos delas serviram de base para a criação do Modelo Poligonal.

Por exemplo, na p. 185, Low afirma que é difícil fazer traduções para serem cantadas "porque o texto meta precisa se encaixar em uma música préexistente - seus ritmos, valores das notas, fraseados e ênfases - enquanto mantém a essência do texto fonte." ${ }^{1}$ Além da presença perigosa do essencialismo, é possível ver como a premissa de Low não se adequa à canção popular, já que, como diz Diniz (2001, p. 215):

A voz do intérprete [...] não indica a superação do material de que ela se
nutre como sustentação de sua própria existência. Mas, sem nenhuma
dúvida, a sua função na cultura contemporânea tem se alterado
rapidamente, e hoje passa a ser entendida como uma das forças
participantes da mecânica de funcionamento da canção [popular].

Diniz defende no texto uma visão diferente acerca da voz do intérprete, pensando em nomes como Caetano Veloso e João Gilberto:

\begin{abstract}
A análise da voz em Caetano não deve ser vista somente em seus aspectos técnicos - afinação, pureza e riqueza na emissão, flexibilidade de extensão. Ela se liga à confirmação de um universo de incorporações e reinvenções, onde a sua potência de releitura articula para um outro nível de percepção os fragmentos rítmicos, os cortes melódicos, os sons que se desatomizam no silêncio, na pausa. Constatamos o poder imagético de uma voz que contamina e se apropria de uma canção, transfigurando-a. Não se trata de uma nuance interpretativa ou a marca de um estilo pessoal. Trata-se sim de longa aprendizagem com o mestre João Gilberto (a qualificação é do próprio
\end{abstract}

\footnotetext{
${ }^{1}$ Quando não houver indicação de tradutor, a tradução é autoral.
} 


\begin{abstract}
Caetano), que tão bem determinou um novo canto, uma construção vocal que não mais pulsava entre agudíssimos trinados e graves registros, como Francisco Alves e Vicente Celestino, deslizando entre pequenas e sutis sístoles e diástoles a sua autolimitada extensão alimítrofe. (ibid., p. 210; grifo do autor)
\end{abstract}

Vê-se no início da citação acima que Diniz defende uma perspectiva diferente daquela que rege o canto lírico: "afinação, pureza e riqueza na emissão, flexibilidade de extensão". O intérprete popular e sua voz estão sujeitos a outros tipos de avaliação, que prezam mais por uma individualidade ou originalidade. Ou seja, por conta do peso dessa marca pessoal do intérprete, "quem determina o caráter da obra é geralmente o intérprete" (ABREU, 2001, p. 111), não o autor, então um encaixe perfeito na "música pré-existente" não se aplica.

Pulando da voz para a melodia, Low não é preciso ao discutir possíveis variações na melodia ao traduzir uma canção, escrevendo que adicionar ou subtrair sílabas "só se pode fazer em lugares aceitáveis" (2005, p. 197). Apesar de ele próprio fazer uma tradução de uma canção popular ("Ne Me Quitte Pas", de Jacques Brel), os exemplos dados são eruditos, pois ele argumenta que essa prática é mais adequada "em um recitativo (por exemplo) do que em uma frase lírica" (ibid.).

Há outro argumento acerca da maior liberdade do mundo popular em relação ao clássico, e ele passa por Zumthor (2018). Ao contar de sua infância em Paris nos anos 1930, o autor remete a uma história em que observava a apresentação de um cantor de rua:

\footnotetext{
Ouvia-se uma ária, melodia muito simples, para que na última copla pudéssemos retomá-la em coro. Havia um texto, em geral muito fácil, que se podia comprar por alguns trocados, impresso grosseiramente em folhas volantes. Além disso, havia o jogo. O que nos havia atraído era o espetáculo. (ZUMTHOR, 2018, p. 28)
}

Após comprar o texto, Zumthor fala de sua frustração ao lê-lo e cantálo, pois esses atos não suscitavam o espetáculo que ele testemunhara e se realizavam, então, como uma ilusão. O teórico, já maduro, chega à seguinte conclusão: 
A forma da canção do meu camelô de outrora pode se decompor, analisar, segundo as frases ou a versificação, a melodia ou a mímica do intérprete. Essa redução constitui um trabalho pedagógico útil e talvez necessário, mas, de fato (no nível em que o discurso é vivido), ele nega a existência da forma. Essa, com efeito, só existe na "performance". (ibid., p. 29)

Para Zumthor, a performance é "o único modo vivo de comunicação poética" (ZUMTHOR, 1990, p. 37 apud MATOS, 2002, p. 142), o que destaca a importância que tem "no processo da produção de sentido e efeito estético" (ibid.). Pois é exatamente no campo da performance que Augusto de Campos acentua a diferença entre o mundo clássico e o popular ao discutir o que seria a música clássica do futuro:

A própria hierarquia tradicional entre compositores, executantes e espectadores está sendo destruída. Três razões. $1^{a \mathfrak{a}}$ : as atividades dos compositores de música "indeterminada", em que os executantes não fazem apenas o que lhes foi mandado fazer, mas têm ensejo de optar e decidir, cooperando com o compositor. (CAMPOS, 2011, pp. 129-130, grifo meu)

E:

Cage acentua que, no caso de grande parte da música popular e de algumas músicas orientais, as distinções entre compositores e executantes nunca foram claras. A partitura não se interpõe entre o músico e a música. As pessoas simplesmente se reúnem e fazem som. Improvisação. Que pode ocorrer dentro das limitações do raga e do tala hindus ou livremente, num espaço de tempo, como os sons do contexto, no campo ou na cidade. E assim como o ritmo a-periódico pode incluir o ritmo periódico, as improvisações livres podem incluir as estritas, e podem até mesmo incluir composições. A Jam Session. O Musicirco. (ibid., p. 130, grifo meu)

No primeiro trecho grifado, o termo "cooperando" é de especial interesse. Os executantes - e não intérpretes -, sob inúmeras amarras histórico-musicais, precisam tocar as peças seguindo a partitura, além de uma série de orientações que não estão na escrita. $\mathrm{O}$ tocar pianístico barroco é completamente diferente do tocar pianístico romântico, por exemplo: o movimento dos dedos, o fluir das frases. Então, quando existe a possibilidade de o executante cooperar com o compositor, abre-se espaço para que o intérprete - agora sim, intérprete - surja.

Na música popular, como a segunda citação indica, essa questão não existe - ou, ao menos, é diferente. Há, sim, uma obra original que o 
intérprete reproduz a seu modo. No entanto, "a seu modo" pode significar uma mudança na instrumentação, no arranjo, no tom, no tipo de voz e, dependo das circunstâncias, na melodia e na letra.

Voltando a Low, na p. 185, ele dá um conselho aos tradutores de canção: "Tradutores são alertados a não terem opiniões a priori que identifiquem que uma característica do texto fonte é sacrossanta: quanto maior o número de margens de flexibilidade, maior é a chance de um resultado bem-sucedido" (grifo do autor). É extremamente acertado o comentário sobre as margens de flexibilidade, porém esse desinteresse pelos elementos mais formais pode levar a traduções que descaracterizam o original, perdendo, por exemplo, as proparoxítonas de "Construção", de Chico Buarque, ou as rimas de "It's Alright, Ma (I'm Only Bleeding)", de Bob Dylan².

Quanto ao sentido, Low afirma que "as limitações das traduções para serem cantadas implicam necessariamente um alargamento ou manipulação do sentido", com "uma definição de precisão aceitável [...] mais ampla" (2005, p. 194). Uma rigidez no aspecto semântico pode ocasionar sacrifícios em outros quesitos. Como as canções são um "fato de comunicação estética dotado de propriedades específicas, relacionadas à interação entre poesia verbal, música e performance vocal" (MEDEIROS, 2001, p. 132), é preciso pensar no todo; não só no sentido, não só na melodia, não só na voz.

Low, inclusive, flerta com o todo no termo "singability" (cantabilidade), ao propor um parâmetro que "exige "performabilidade" (2005, p. 192). Ele se limita a dizer que a tradução "precisa funcionar eficientemente como um texto oral cantado em uma velocidade de performance" (ibid.) e que, além de ter atenção às questões fonéticofonológicas da língua de chegada, é necessário se atentar ao fraseado dos versos. Já Franzon (2008, p. 375) expande um pouco essa definição de cantabilidade, unindo a ideia de Low à "realização da unidade músicoverbal entre o texto e a composição", já que é isso "que faz a letra 'cantar', por assim dizer, é o responsável por transportar o sentido e, junto à música,

\footnotetext{
${ }^{2}$ Como será mostrado adiante, Dylan tem uma predileção para que suas rimas sejam mantidas.
} 
transmitir a mensagem" (ibid.). No entanto, faltam exemplos práticos do que seria uma canção traduzida com uma cantabilidade alta ou baixa.

$\mathrm{O}$ modelo proposto neste artigo advém dos comentários acima, e cada elemento - melodia, forma, sentido e cantabilidade - será discutido em uma subseção. Ao final, será analisada a tradução de uma canção a partir dos critérios estabelecidos pelo modelo, cujo enfoque é em canções populares. As exigências para traduzir, por exemplo, uma ópera, são outras, então seria necessário adotar outras ferramentas ou fazer adaptações a esta.

\section{Melodia}

A resposta para a pergunta "quais os lugares aceitáveis onde se pode variar a melodia na tradução?" não deve ser encarada de forma binária, aceitando apenas "aqui é permitido" e "aqui não é permitido"; uma visão mais relativa, consequente também da influência da marca pessoal do intérprete, dá mais flexibilidade ao tradutor. Assim, pode-se pensar em um eixo horizontal com a seguinte lógica: quanto mais à esquerda, mais cantada é a melodia; quanto mais à direita, mais falada. Uma ilustração simples:

\section{Cantada $\longrightarrow$ Falada}

Com isso, o tradutor pode adotar critérios para posicionar a canção (ou as canções) que for traduzir e ter uma ideia melhor do nível de variação que ele pode se permitir. Pensando nos polos, nos tipos de música que são (ou quase são) exclusivamente cantados ou são (ou quase são) exclusivamente falados, encontra-se o seguinte:

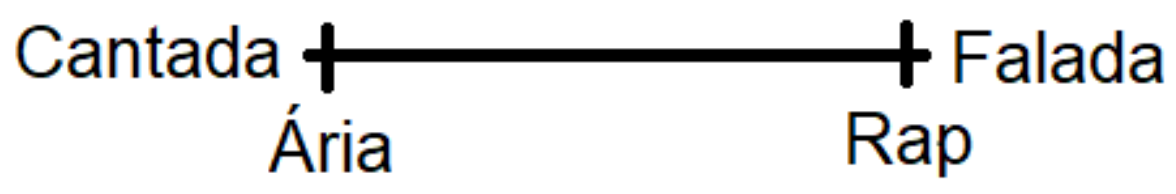

Como já dito antes, este artigo não pretende entrar em detalhes da tradução de música clássica, e o posicionamento da ária, um tipo de música 
vocal para um cantor solista, na extrema esquerda, já mostra o peso que a melodia tem. Já no rap, que é obviamente um gênero de música popular, o principal é acompanhar o ritmo, para que os versos traduzidos ocupem o mesmo número de compassos do original. A partir disso, depreende-se que:

1) quanto mais à esquerda, mais importância tem a melodia, aqui definida como uma sequência determinada de notas possível de ser apreendida e reproduzida (cantarolando ou assobiando, por exemplo) mesmo sem letra. Podemos afirmar também que a altura e a duração das notas têm o mesmo peso; e

2) quanto mais à direita, mais a altura das notas vai perdendo sua importância, e o que predomina é a duração. Assim, o compasso se torna a unidade a ser obedecida, e praticamente não há uma melodia que possa ser reproduzida na ausência da letra.

Pensando agora em termos da tradução, à esquerda, o tradutor encontra-se no domínio da melodia, necessitando seguir uma sequência de notas específica e pré-delimitada; à direita, ele se vê no domínio do compasso, encaixando os versos no mesmo número de compassos da canção original. Há também o centro, o espaço do desenho melódico, que são as subidas e descidas da melodia, as repetições de fraseado etc. Canções traduzidas pelo contorno melódico permitem alguma variação na melodia original, determinada contextualmente pelas características da obra. No entanto, uma questão que se deve ter sempre em mente ao alterar a melodia é a da harmonia. É preciso se assegurar de que notas acrescentadas ou subtraídas não vão alterar a estrutura harmônica da obra ${ }^{3}$.

Não há fronteiras absolutas entre o que se considera esquerda, direita e centro, de modo que fica a cabo do tradutor decidir, com base em elementos da canção original, a abordagem a ser feita. Por exemplo, o tradutor pode pensar nos intervalos entre as notas - há saltos muito grandes ou as notas estão mais próximas? -, nas frases — há muita repetição melódica? - etc.

\footnotetext{
${ }^{3}$ Uma alteração assim não se compara a simplesmente mudar o tom da canção, que faria com que todos os acordes da obra subissem ou descessem proporcionalmente, mantendo ainda a relação original entre eles. A crítica aqui se dirige a variações na melodia que acabem por adulterar a harmonia, desfazendo essa relação.
} 
A flexibilidade que o eixo permite ao tradutor não está só na tipificação melódica, como na abordagem adotada. Essa liberdade, por outro lado, exige atenção e cuidado, mas o que o tradutor pode ter mente, independentemente da localização da canção no eixo, é que na tradução "um número idêntico de sílabas é desejável" (LOW, 2005, p. 197).

\title{
Forma
}

Ao tratar de questões formais, Low se atém a falar de rima e de naturalidade/ordem de palavras e registro, quando uma canção pode ter elementos estruturais variados. "Construção", como já afirmado antes, termina sempre com proparoxítonas:

Amou daquela vez como se fosse a última

Beijou sua mulher como se fosse a última

E cada filho seu como se fosse o único

E atravessou a rua com seu passo tímido

E “It's Alright, Ma (I'm Only Bleeding)" tem um esquema de rimas que precisa ser seguido:

\author{
Darkness at the break of noon \\ Shadows even the silver spoon \\ The handmade blade, the child's balloon \\ Eclipses both the sun and moon \\ To understand you know too soon \\ There is no sense in trying 4
}

As rimas são muito importantes para Dylan. Na edição alemã das traduções das letras do cancionista, os tradutores abrem o livro com um comentário sobre o trabalho:

\footnotetext{
${ }^{4} \mathrm{O}$ esquema de rimas mais completo seria aaaaab cccccb dddddb eeb, que se repete três vezes ao longo da canção.
} 
No contrato de licença para esta edição alemã, Bob Dylan exigiu que as rimas originais, na medida do possível, devessem ser preservadas. Assim, fazer uma tradução livre se torna problemático. Em muitos casos, as palavras originais foram alteradas. É claro que há muito a ser discutido sobre até que ponto se pode ou se deve ir. Tentamos manter as mudanças dentro de limites aceitáveis, mas sem fazer o trabalho só pela metade.

(DYLAN, 1985, p. 4)

O peso que elementos formais podem ter em canções é muito alto, mas alguma flexibilidade é necessária. No exemplo de “It's Alright, Ma (I'm Only Bleeding)", o tradutor pode optar por não usar exclusivamente oxítonas. Já em "Construção", a ideia é que se termine os versos com palavras de alguma forma marcadas e intercambiáveis, como no original.

Como foi apresentado para a melodia, concebe-se um eixo similar para a forma:

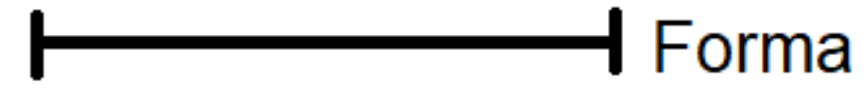

Forma pouco Forma muito

importante importante

A inversão paramétrica, com o peso recaindo para o lado direito, será explicada adiante, quando o esquema for integralmente montado.

\section{Sentido}

Até que ponto trocar uma expressão por uma palavra é uma mudança de sentido? Como esquematizar algo assim? Para o sentido, sugere-se pensar em uma espécie de argumento, como se faz no cinema. Ao fazer o argumento de uma canção, o tradutor já separa os elementos que vai priorizar, deixando clara uma hierarquia.

Uma possibilidade de argumento para "Construção" seria: "uma canção que fala do último dia de vida de um peão de obra, que cai de um prédio e morre no asfalto". No entanto, essa opção não dá detalhes da forma, um elemento importante, então poder-se-ia precisar mais ainda o argumento: “uma canção que fala do último dia de vida de um peão de obra, 
que se despede da mulher e dos filhos e cai de um prédio e morre no asfalto. Ela é escrita em versos dodecassílabos terminados em proparoxítonas."

Onde o primeiro exemplo peca por falta, este peca por excesso, mas, novamente, quem define os limites do argumento é o tradutor. A ideia é que, ao explicitar os elementos que compõem a canção, o tradutor flexibiliza a noção de sentido para abarcar o que ele achou mais importante.

Igualmente ao que foi feito para os dois elementos anteriores, segue abaixo o eixo referente ao sentido. Desta vez, o peso recai para a maior ou menor referencialidade do conteúdo da letra:



Por "referencial", entenda-se aqui como descrições físicas de personagens, pessoas, lugares e objetos, marcas da passagem de tempo etc.

\title{
Cantabilidade
}

O que ambos os trechos a seguir têm em comum?

\author{
Jesus Cristo, Jesus Cristo \\ Jesus Cristo, eu estou aqui \\ É preciso saber viver
}

Além de serem de canções de Roberto Carlos - "Jesus Cristo" e "É Preciso Saber Viver", esta composta com Erasmo Carlos -, ambos têm acentos um pouco curiosos. "Jesus" é oxítona, mas Roberto canta como se fosse paroxítona ("Jê-sus", não "Je-sús"); o mesmo ocorre com "saber" e "viver" do segundo exemplo. Podemos entender melhor colocando os excertos em questão em uma tabela, onde cada coluna representa uma batida da canção e cada linha, um compasso: 


\begin{tabular}{|l|l|l|l|}
\hline$/ / /$ & $/$ & $/ /$ & $/$ \\
\hline Je- & sus & Cris-to & \\
\hline Je- & sus & Cris-to & \\
\hline Je- & sus & Cris-to, & Eu es- \\
\hline tou & a- & qui & \\
\hline
\end{tabular}

\begin{tabular}{|l|l|l|l|}
\hline$/ / /$ & $/$ & $/ /$ & $/$ \\
\hline É & pre & ci & so \\
\hline sa-ber & vi-ver- & - & - \\
\hline
\end{tabular}

"Jesus Cristo" e "É Preciso Saber Viver" têm um tempo de 4/4, onde a primeira batida é a mais forte, a terceira é menos forte e a segunda e a quarta são fracas. A força das batidas é indicada pelo número de barras na primeira linha das respectivas tabelas.

O que aqui é chamado de "cantabilidade" está mais relacionado ao conceito de Franzon, que fala "da unidade músico-verbal entre o texto e a composição" (2008, p. 375). Pode-se pensar na cantabilidade como uma coincidência entre os acentos das palavras da letra com os tempos fortes dos compassos da canção. Mais especificamente, em termos de tradução, a cantabilidade é "a possibilidade de que a letra traduzida seja cantada na melodia original, ou em uma melodia que não se afaste da original a tal ponto que os ouvintes a considerem uma melodia diferente" (BRITTO, 2018, p. 1).

Britto formula, então, uma regra frisando um bom entendimento da letra da parte do ouvinte: "nenhum tempo forte da canção deve incidir sobre uma sílaba átona da letra" (ibid., p. 5). A partir disso, pode-se pensar em outra regra: uma sílaba acentuada pode coincidir com um tempo fraco. Essas duas regras são a base para julgar a cantabilidade de uma canção traduzida.

Isso não significa, porém, que um problema de cantabilidade no original precise ser reproduzido na tradução. Caso "Jesus Cristo" fosse traduzido para outro idioma, seria desnecessário reproduzir o descompasso; o inverso se aplica em "Épico", de Caetano Veloso, em que ele canta "Sinto cálor, sinto frio", imitando o estilo dos cantores populares nordestinos. Neste 
caso, o defeito de prosódia é calculado, pois ele quer imitar o estilo de um cantor folclórico.

Finalmente, o último elemento ganha também um eixo:

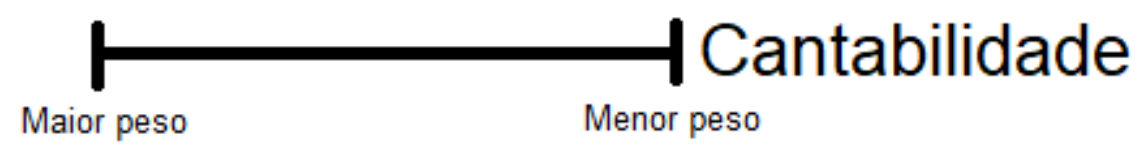

\section{O polígono}

Juntando os quatro eixos já apresentados, forma-se o modelo:

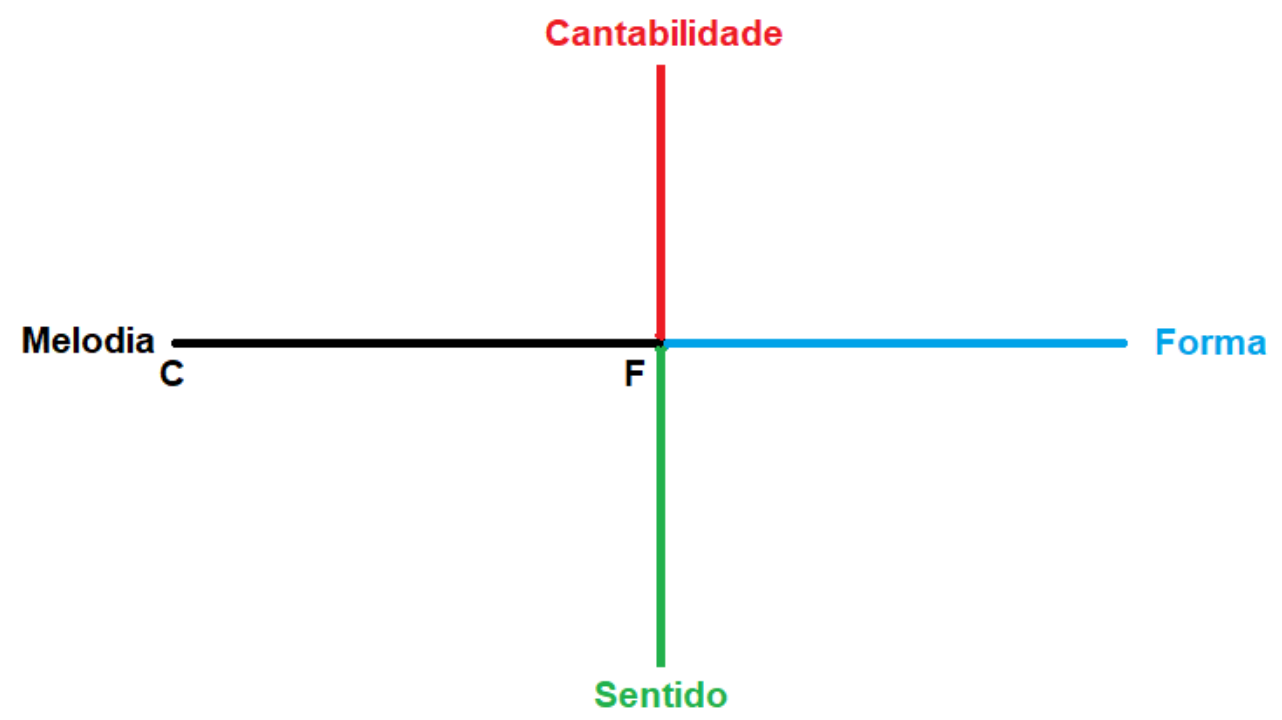

Marcam-se as canções como abaixo:

- o eixo de melodia mantém a orientação, com as melodias mais cantadas à esquerda e as mais faladas à direita;

- no eixo da cantabilidade, quanto mais alta for a marcação, mais importante é a cantabilidade naquele gênero musical;

- no eixo da forma, quanto mais à direita, mais fixa e, consequentemente, mais importante, é a forma para a tradução; e

- no eixo do sentido, quanto mais baixa a marcação, mais elementos semânticos de grande peso a canção tem. 
Entretanto, o modelo mostra-se pouco preciso. Gradações são necessárias:

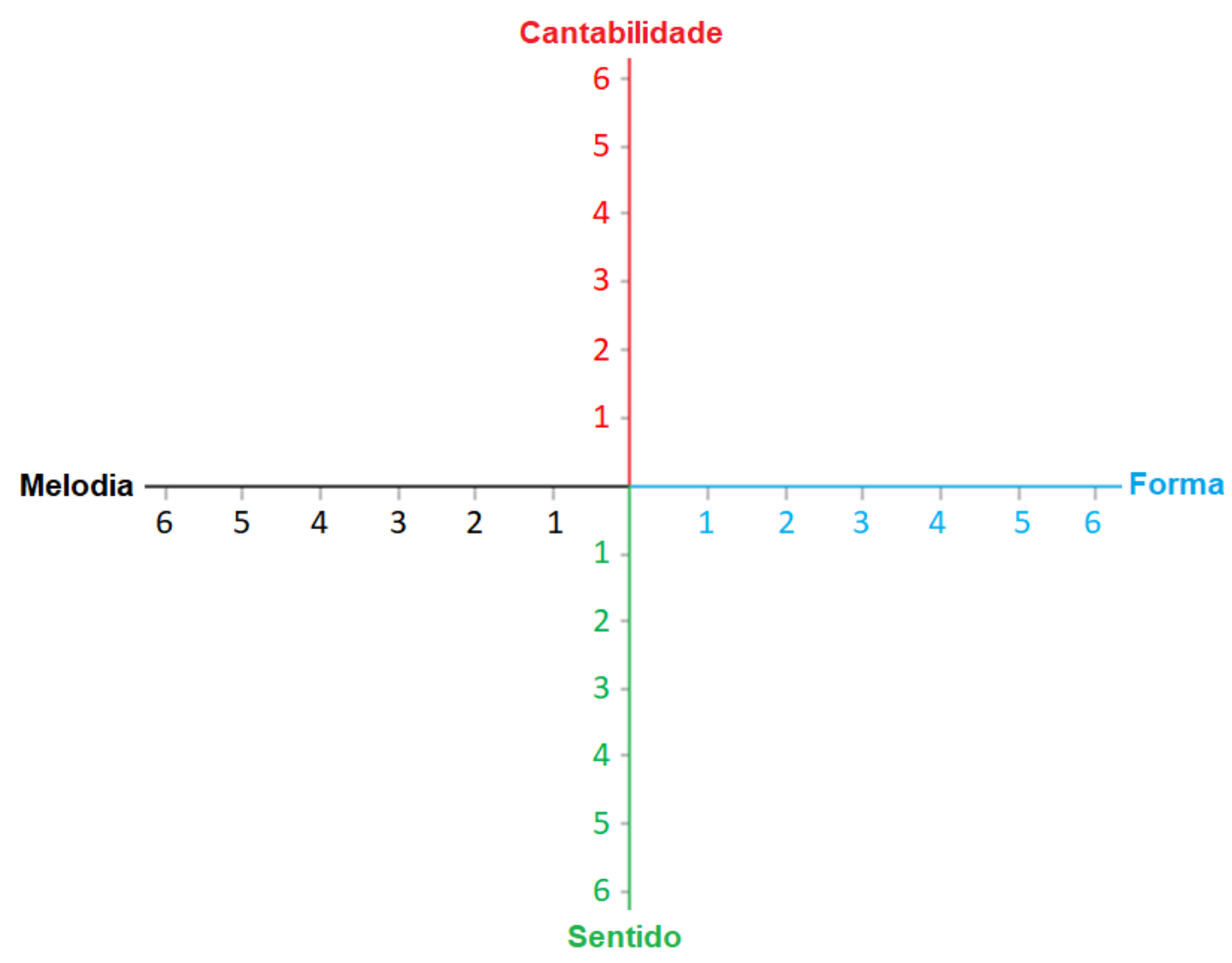

A escolha por seis pontos por eixo se dá por dois fatores:

1) Com um número relativamente baixo de gradações, situar o peso de cada elemento nos eixos fica mais fácil.

2) Para a canção original, só se usaria as gradações de três a seis. Os graus um e dois estão presentes para que se sinalizem possíveis perdas na tradução. Como o mesmo gráfico será usado para o original e para a tradução, é importante poder assinalar diferenças assim.

Na próxima subseção, o modelo entrará em ação com uma análise da canção "Man Gave Names to All the Animals", de Bob Dylan, e a tradução feita por Zé Ramalho, intitulada "O Homem Deu Nome a Todos Animais", gravada por ele próprio para o CD Zé Ramalho Canta Bob Dylan - Tá Tudo Mudando, de 2008. 


\section{"Man Gave Names to All the Animals"}

Escrita durante o período evangélico de Dylan, a canção se baseia em dois versículos bíblicos, Gênesis 2:19-20 (p. 6):

19 E formou o Eterno Deus, da terra, todo animal do campo e toda ave dos céus, e trouxe ao homem para ver como os chamaria; e tudo o que chamaria o homem à alma viva, esse seria o seu nome.

20 E o homem deu nomes a todo quadrúpede e ave dos céus e a todo animal do campo [...].

Na letra, Dylan dedica cada uma das estrofes, com exceção do estribilho, repetido seis vezes, a um animal diferente, sempre com a mesma estrutura de rimas - $a a b b$ - e sempre deixando para revelar o nome do animal no quarto verso, guardando os outros três para características físicas ou fisiológicas. Por exemplo, o primeiro animal mencionado é o urso:

\footnotetext{
He saw an animal that liked to growl

Big furry paws and he liked to howl

Great big furry back and furry hair

"Ah, think I'll call it a bear"
}

A exceção é a última estrofe:

He saw an animal as smooth as glass

Slithering his way through the grass

Saw him disappear by a tree near a lake...

Que animal seria? Há algumas pistas, como o fato de a canção ter sido escrita no período evangélico, ou seja, é carregada de influência bíblica, e o terceiro verso, que termina com "lake". O animal é descrito como "liso como vidro" e que "se arrasta pela grama". O único animal que se encaixa é "snake", a serpente. Segundo Danieli \& Biletki (2006, p. 91), a ausência da cobra "é onde a canção quer chegar". Eles explicam: "No contexto bíblico 
estrito, dentro da tradição judaico-cristã exegética, dar um nome significa sempre e invariavelmente o domínio de quem deu o nome sobre a coisa ou pessoa nomeada" (ibid.) A serpente, então, ao não ser nomeada pelo homem, significa que não está sujeita a ele. Além disso, a serpente é tida como "a fonte do pecado original, a responsável pela queda do homem da graça divina e por sua expulsão do Paraíso" (ibid., p. 92). Os autores concluem:

\footnotetext{
Então, em um contexto bíblico estrito, puramente dentro da tradição religiosa, a canção de Dylan parece estar mandando uma mensagem simples, mas mordaz: o homem não tem domínio sobre sua inclinação maligna. Com a canção terminando abruptamente ao expressar isso, o silêncio consequente parece implicar que se trata do oposto, e é a inclinação maligna que tem domínio sobre o homem. (ibid.)
}

Ou seja, não nomear a serpente no final, mas ainda deixar indícios da presença dela, é uma parte muito importante da canção, algo a ser mantido em uma tradução.

Quanto à melodia, Dylan emprega um estilo de frase nas estrofes dos animais e outro tipo de frase no estribilho. Uma boa saída, então, é pensar em traduzir pelo desenho melódico, pois assim o tradutor terá mais flexibilidade para traduzir a letra.

Como se trata de uma canção popular, o nível de cantabilidade é alto, ainda mais por se tratar de Bob Dylan. É imprescindível que se possa entender o que está sendo cantado.

Em resumo, gradar-se-ia os quatro elementos de tal forma:

- melodia: 5ํㅡㅁ grau; afinal, há muitas frases melódicas sendo repetidas com variações;

- cantabilidade: $5^{\circ}$ grau, já que o gênero canção popular exige clareza na transmissão do conteúdo;

- forma: $5^{\circ}$ grau, pois a canção apresenta uma forma fixa, com quadras de esquema de rimas aabb e um estribilho. É possível também mudar o esquema de rimas, necessitando apenas repeti-lo ao longo da canção.

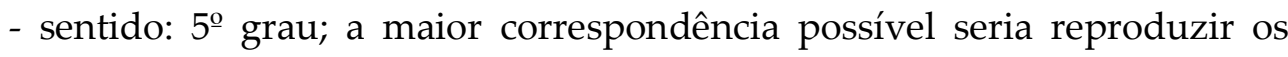
mesmos animais na mesma ordem, mas, para uma maior flexibilidade, é possível pensar apenas em mamíferos quadrúpedes. A exceção é que o animal final seja a serpente, ainda que sem nomeá-la. Em termos de 
argumento, poderíamos pensar: uma canção com influências bíblicas, mais especificamente de Gênesis 2:19-20, que descreve uma série de mamíferos quadrúpedes usando estrofes rimadas. O último animal a ser descrito é a serpente, que acaba não sendo nomeada.

Ao plotar esses elementos no gráfico, encontra-se a seguinte análise:

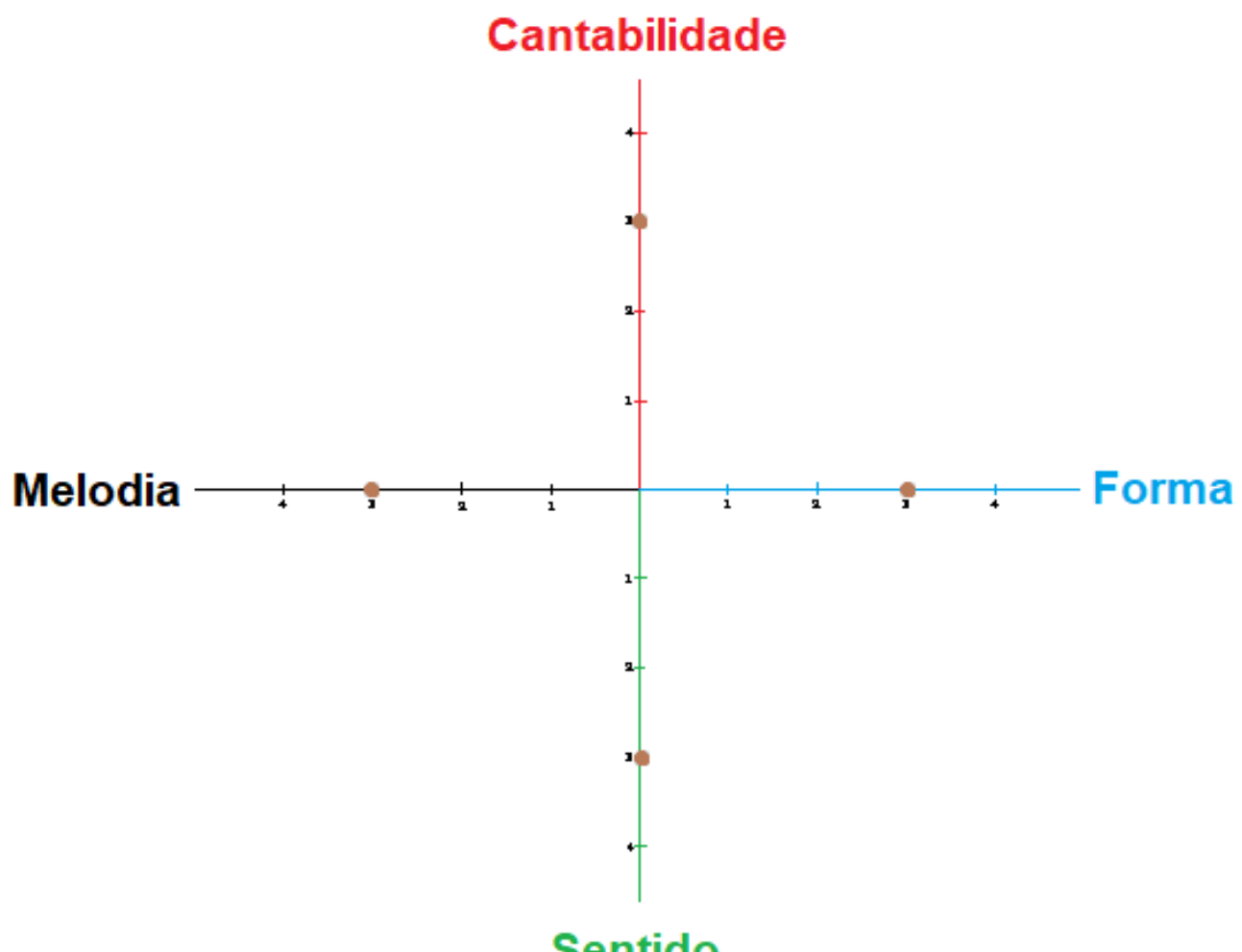

E, ao ligar os pontos, forma-se o polígono: 


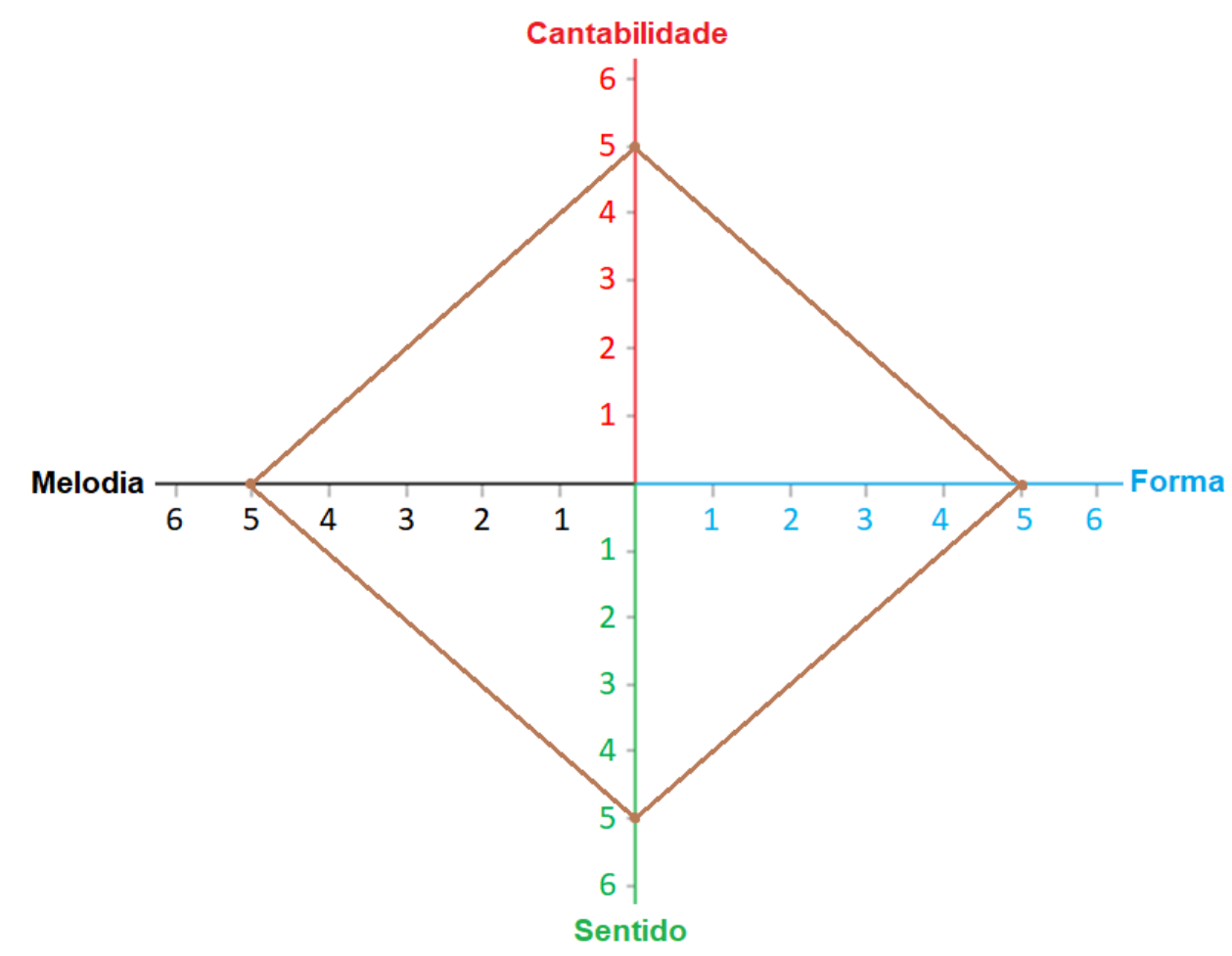

Isto é mais que um auxílio visual, pois, ao julgar a tradução pelos mesmos parâmetros, podem-se comparar os polígonos. Em outras palavras, a divergência entre os polígonos refletiria o grau de perda envolvido na tradução. O ideal é que o polo da convergência fosse sempre o mais distante do centro, de modo que em uma tradução pouco fiel o polígono da tradução seria bem menor que o do original.

Dito tudo isso, é hora de ver a tradução que Zé Ramalho fez.

\section{"O Homem Deu Nome a Todos Animais"}

Segue abaixo a letra traduzida, transcrita da canção:

O homem deu nome a todos animais

Desde o início, desde o início

O homem deu nome a todos animais

Desde o início, há muito tempo atrás

[refrão]

Viu um animal com tal poder

Garras afiadas e um porte 
Quando rugia, tremia o chão

Disse com razão: chamar-se-á leão

[refrão]

Viu um animal que era tão manso

Puro, lindo, nenhum mal fará

Mas seu predador, que não é bobo

Vou chamar de lobo e sempre o caçará

Era a ovelha

[refrão x 2]

Viu outro animal se alimentar

No peito da mãe, seu leite a sugar

Viu que aquela fêmea não é fraca

D'outras se destaca e a chamou de vaca

[refrão]

Viu uma criatura se arrastando

No chão, sibilando lentamente

Só não percebeu foi o veneno

Dentro do seu dente

Mas a chamou serpente

[refrão]

Logo se percebe que Zé Ramalho reduziu o número de animais: dos cinco originais (urso, vaca, touro, porco, ovelha), ficaram apenas três (leão, ovelha, vaca). Desses três, apenas dois - a ovelha e a vaca - apareciam no original. O leão foi um acréscimo de Zé Ramalho, talvez para ter uma rima 
fácil. Independentemente da motivação, essa mudança, como indicado acima, não tem um peso tão grande assim. O leão, como todos os outros animais, é um mamífero quadrúpede. O que pesa, porém, é a diminuição do número de animais.

Falando em rima, a tradução de Zé Ramalho começa aparentemente criando um novo esquema rímico, o xxaa, em que os dois primeiros versos não são rimados, apenas os dois últimos. Porém, na estrofe do animal seguinte, o esquema proposto pelo tradutor já mudou: xaxax. Na estrofe da vaca, Zé Ramalho usa o esquema original de Dylan, aabb, mas, na estrofe da serpente, as rimas mudam novamente: $x a a^{\prime} b b$. Novamente, foi acrescido um quinto verso. A rima é importante nesta canção porque, desde o início, ela orienta o ouvinte acerca das descrições e das nomeações. Quando o esquema é constantemente modificado, o ouvinte perde uma âncora.

Voltando aos casos de acréscimo, ambos são problemáticos, mas por razões diferentes. A estrofe da ovelha viola uma parte do argumento: as influências bíblicas. Como diz o Gênesis 1:30: “'E para todo animal da terra e toda ave dos céus, e tudo o que se arrasta sobre a terra, em que haja alma viva; e toda verdura de erva (será) para comer'. E foi assim." (BÍBLIA, 2001, p. 4). O comentário acerca do versículo confirma: “A princípio, Deus concedeu ao homem comer verduras e frutas, e aos animais ervas. Mais tarde, porém, permitiu-lhe comer também a carne de animais (vide Gênesis 9:3)" (ibid.). Ou seja, no Paraíso ainda não se consumia carne, apenas plantas, então não é possível dizer que o lobo era o predador da ovelha. Esse detalhe mostra a importância de fazer um argumento com os detalhes certos. Ignorar (ou desconhecer) a potência bíblica em "Man Gave Names to All the Animals" pode empobrecer a tradução ou levar o tradutor a enganos como esse.

A outra estrofe de cinco versos é a da serpente, e Zé Ramalho nomeia o animal, se opondo à parte mais importante da canção, como Danieli \& Biletzki apontaram. Apesar de não ser estritamente uma questão bíblica, este era outro detalhe apontado no argumento. A serpente não podia ser nomeada. Curiosamente, Adriana Calcanhotto, sob o heterônimo Adriana Partimpim, em seu disco infantil Partimpim Dois, gravou esta canção, mas 
sabiamente omitiu o verso da serpente. Uma possibilidade é o seu pretendido público-alvo.

Surge outra pergunta: é preciso necessariamente que a canção acabe após a não nomeação da serpente? A versão de estúdio de Dylan acaba, mas a de Zé Ramalho e a de Adriana Partimpim não. É uma questão de menor importância do que a da serpente, pois o próprio Dylan, em ao menos uma apresentação, repete o refrão no final. Por exemplo, no show no Paramount Theatre, em Portland, Oregon, em 16 de janeiro de 1980, quando chega o fatídico verso, Dylan cantarola, enquanto suas backing vocals fazem um som sibilante, imitando o animal, e logo em seguida eles engatam em uma repetição do refrão, como atesta o boxset The Bootleg Series Vol. 13: Trouble No More 1979-1981.

Há também outros problemas não decorrentes do argumento. A estrofe da vaca tem duas opções tradutórias que merecem ser discutidas. Zé Ramalho começa falando do animal que suga o leite da mãe, mas termina a estrofe falando da mãe, afirmando que ela se destaca das outras fêmeas. No original, não há situação similar; cada estrofe se dedica apenas a um animal ${ }^{5}$. Ademais, a vaca não tem "peito" para o bezerro sugar, e sim "tetas". Por fim, o emprego no refrão de "há muito tempo atrás" altera um pouco com o registro. Apesar do original ter um registro informal, com descrições às vezes quase infantis, o pleonasmo na tradução é desnecessário. Pode-se falar também da mistura de tempos verbais, pois Zé Ramalho usa presente ("vou chamar"), passado ("a chamou") e futuro ("chamar-se-á"), enquanto Dylan fala apenas no presente: "think I'll call it".

A cantabilidade, apesar de alguns deslizes ("era tão manso" cantada como "erá tão manso" e "no peito da mãe" cantado como "nú peitú da mãe", entre outros) não comprometeu o entendimento. Também não se pode dizer que a melodia sofreu alterações que a descaracterizassem, mas os acréscimos nas estrofes de cinco versos chamam atenção, porque não são substituições ou variações. Zé Ramalho teve que adicionar uma melodia onde não havia.

Como, então, comparar original e tradução? Cantabilidade e melodia continuam no $5^{\underline{0}}$ grau. Os acréscimos melódicos não são suficientes para

\footnotetext{
${ }^{5}$ Há o mesmo na estrofe da ovelha, com a relação dela com o lobo, outro porém.
} 
alterar tanto assim a canção, e os poucos desvios de cantabilidade em nada prejudicam. A forma, na tradução, caiu para o $3^{\circ}$ grau. As alterações feitas alteram a forma, não sendo mais possível antecipar a serpente. O sentido também cai para o $3^{\circ}$ grau, por conta da inclusão da serpente e do erro bíblico referente à caça no Éden.

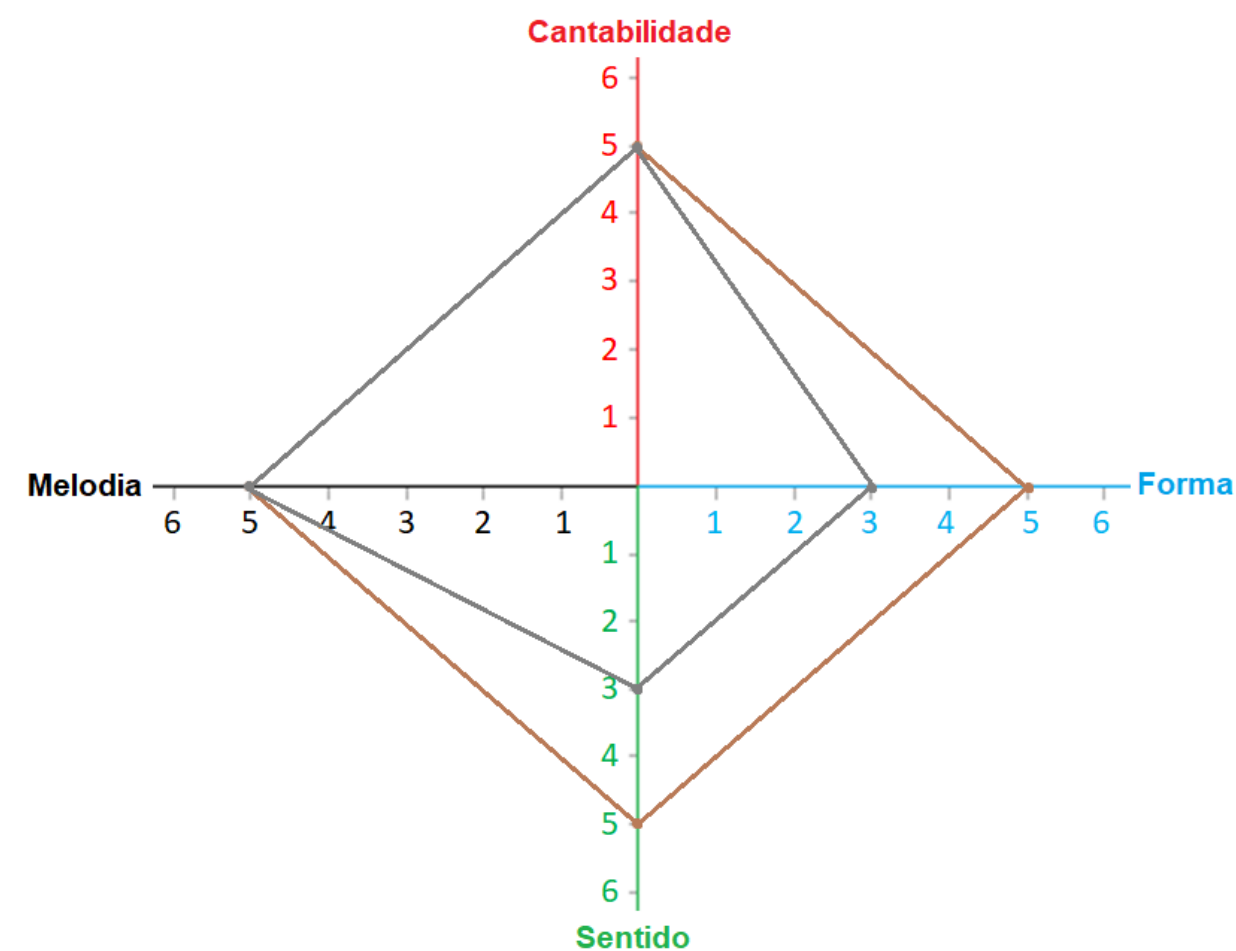

Finalmente, segue o gráfico comparando original (marrom) e tradução (cinza):

O gráfico acima ajuda a visualizar os polígonos e pensar em quais parâmetros a tradução poderia melhorar e em quais o tradutor tomou decisões acertadas. Pela justificativa acima, mostro porque o polígono de Zé Ramalho está muito menor que o original, um sinal de que o grau de perda está relativamente alto.

\section{Conclusão}

O modelo poligonal, que partiu de observações acerca do pentatlo de Low, serve não só para apontar parâmetros para uma tradução de uma canção 
popular, mas também para visualizar as diferenças desses elementos entre o original e a tradução, de forma a facilitar a análise do grau de perda. $\mathrm{O}$ polígono do exemplo analisado, a tradução de "Man Gave Names to All the Animals", intitulada "O Homem Deu Nome a Todos Animais", tem uma diferença grande em relação ao da canção original.

Essa visualização, porém, não substitui uma justificativa verbal, apenas a acompanha. É uma simplificação visual e uma ferramenta que precisa da força da palavra para mostrar sua utilidade.

\section{Referências}

ABREU, Felipe. A questão da técnica vocal ou a busca da harmonia entre música e palavra. In: MATOS, Cláudia Neiva de; TRAVASSOS, Elizabeth; MEDEIROS, Fernanda Teixeira de (Orgs.). Ao encontro da palavra cantada: poesia, música e voz. Rio de Janeiro: 7Letras, 2001, p. 104-112. BÍBLIA, V. T. Gênesis. Português. Torá: A lei de Moisés. Tradução do rabino Meir Matzliah Melamed. São Paulo: Editora e Livraria Sêfer, 2001, p. 1-150. BRITTO, Paulo Henriques. A Tradução da Letra de Canção. Disponível em: http://www.letras.pucrio.br/media/filemanager/professores/paulo_britto/A\%20traducao $\% 20 \mathrm{da} \% 2$ 0letra\%20de\%20cancao.pdf. Acesso em: 31 mai. 2019.

BUARQUE, Chico. Construção. In: Construção. Phonogram/Philips, 1971. CAMPOS, Augusto de. Música de invenção. São Paulo: Perspectiva, 2007. CARLOS, Roberto. Jesus Cristo. In: Roberto Carlos. CBS Records, 1970. CARLOS, Roberto; CARLOS, Erasmo. É Preciso Saber Viver. In: Roberto Carlos. CBS, 1974.

DANIELI, Ruvik; BILETZKI, Anat. We Call It a Snake: Dylan Reclaims the Creative Word. In: VERNEZZE, Peter; PORTER, Carl J. (Eds.) Bob Dylan and philosophy: it's alright, ma (I'm only thinking). Chicago: Open Court, 2006.

DINIZ, Júlio. A voz como construção identitária. In: MATOS, Cláudia Neiva de; TRAVASSOS, Elizabeth; MEDEIROS, Fernanda Teixeira de (Orgs.). Ao encontro da palavra cantada: poesia, música e voz. Rio de Janeiro: 7Letras, 2001, p. 207-216. 
DYLAN, Bob. It's Alright, Ma (I'm Only Bleeding). In: Bringing It All Back Home. Columbia, 1965. O Homem Deu Nome a Todos Animais. Trad. Zé Ramalho. In: Zé Ramalho Canta Bob Dylan - Tá Tudo Mudando. EMI, 2008. O Homem Deu Nome a Todos Animais. Trad. Zé Ramalho. In: Partimpim Dois. Sony Music, 2009. Man Gave Names to All the Animals. In: Slow Train Coming. Columbia, 1979. Man Gave Names to All the Animals. In: The Bootleg Series Vol. 13: Trouble No More 1979-1981. Columbia, 2017. Songtexte 1962-1985. Trad. Carl Weissner e Walter Hartmann. Frankfurt: Zweitausendeins, 1987.

FRANZON, Johan. Choices in Song Translation: Singability in Print, Subtitles and Sung Performance. The Translator, Manchester, v. 14, n. 2, p. 373-399, 2008.

LOW, Peter. The Pentathlon Approach to Translating Songs. In: GORLÉE, Dinda L. (Ed.) Song and Significance: Virtues and Vices of Vocal Translation. Amsterdã: Rodopi, 2005, p. 185-212.

MATOS, Cláudia Neiva de. Anotações para um estudo da palavra poética cantada. In: REIS, Lívia de Freitas; PARAQUETT, Márcia (Orgs.). Fronteiras do literário II. Niterói: Editora da Universidade Federal Fluminense, 2002, p. 133-148.

MEDEIROS, Fernanda Teixeira de. 'Pipoca moderna': uma lição estudando canções e devolvendo a voz ao poema. In: MATOS, Cláudia Neiva de; TRAVASSOS, Elizabeth; MEDEIROS, Fernanda Teixeira de. (Orgs.). Ao encontro da palavra cantada: poesia, música e voz. Rio de Janeiro: 7Letras, 2001, p. 128-140.

RIBEIRO, Hugo L. Uma proposta prática de como abordar o repertório da música do Século XX no ensino superior de música, Música em Contexto, Brasília, n. 1, p. 173-201, 2017.

VELOSO, Caetano. Épico. In: Araçá Azul. Phillips Records, 1973.

ZUMTHOR, Paul. Performance, recepção, leitura. Trad. Jerusa Pires Ferreira e Suely Fenerich. São Paulo: Ubu Editora, 2018. 


\section{Resumo}

O Modelo Poligonal, criado a partir do Pentathlon de Peter Low (2005), é uma ferramenta dupla para o tradutor de canção popular: aponta quatro parâmetros de análise e propõe uma visualização simples para comparar original e tradução. O modelo é colocado em prática com um estudo de "O Homem Deu Nome a Todos Animais", tradução que Zé Ramalho fez da canção "Man Gave Names to All the Animals", de Bob Dylan.

Palavras-chave: Tradução de canção; Bob Dylan; Peter Low; Modelo poligonal.

\section{Abstract}

The Polygonal Model, which came about from Peter Low's Pentathlon Principle (2005) is a double-sided tool for translators of popular music: it highlights four parameters for analysis and proposes a simple visualization in order to compare the original song and its translation. The model is put in practice with commentaries on "O Homem Deu Nome a Todos Animais", a translation to Brazilian Portuguese that Zé Ramalho did of the Bob Dylan original "Man Gave Names to All the Animals".

Keywords: Song translation; Bob Dylan; Peter Low; Polygonal model. 